\title{
Best in Class or Simply the Best? The Impact of Absolute Versus Relative Ecolabeling Approaches
}

\author{
Stefanie Lena Hille ${ }^{1}$, Christian Geiger ${ }^{2}$, Moritz Loock $^{3}$ and John Peloza ${ }^{4}$ \\ ${ }^{1}$ Stefanie Lena Hille \\ Assistant Professor of Energy Consumer Behaviour \\ University of St. Gallen \\ Institute for Economy and the Environment \\ Tigebergstrasse 2, 9000 St. Gallen, Switzerland \\ Phone: +41- 774161137 \\ E-mail: stefanie.hille@unisg.ch \\ ${ }^{2}$ Christian Geiger \\ University of St. Gallen \\ Institute for Economy and the Environment \\ Tigebergstrasse 2, 9000 St. Gallen, Switzerland \\ E-mail: christian.geiger@unisg.ch \\ ${ }^{3}$ Prof. Dr. Moritz Loock \\ Assistant Professor of Energy and Sustainability Management \\ University of St. Gallen \\ Institute for Economy and the Environment \\ Tigebergstrasse 2, 9000 St. Gallen, Switzerland \\ E-mail: moritz.loock@unisg.ch \\ ${ }^{4}$ Prof. John Peloza \\ Associate Professor of Marketing \\ University of Kentucky \\ Department of Marketing and Supply Chain, \\ Gatton College of Business \& Economics \\ 435P Lexington, KY 40506
}

\section{Acknowledgement :}

Stefanie Lena Hille is Assistant Professor of Energy Consumer Behaviour, Institute for Economy and the Environment, University of St. Gallen (e-mail: stefanie.hille@unisg.ch). Christian Geiger was a graduate student at the University of St. Gallen (e-mail: christian.geiger@unisg.ch). Moritz Loock is Assistant Professor of Energy and Sustainability Management, Institute for Economy and the Environment, University of St. Gallen (e-mail: moritz.loock@unisg.ch). John Peloza is Associate Professor of Marketing, Gatton College of Business and Economics, University of Kentucky (e-mail: john.peloza@uky.edu). This research is part of the activities of SCCER CREST (Swiss Competence Center for Energy Research), which is financially supported by the Swiss Commission for Technology and Innovation (CTI) under Grant No. 466 KTI.2014.0114. The authors thank the anonymous JPPM review team for valuable feedback. 


\title{
Best in Class or Simply the Best? The Impact of Absolute Versus Relative Ecolabeling Approaches
}

\begin{abstract}
Although research has widely investigated labels across a range of product domains, one understudied area is the use of absolute versus relative rating approaches to information provision. For example, under an absolute rating approach to vehicle ecolabels, the consumer is informed of the actual amount of fuel consumed during use of a vehicle compared with that of all other vehicles on the market. Under a relative rating approach, the fuel consumption is communicated in relative terms, comparing the vehicle only with others in the same class. The current research illustrates that switching from an absolute to a relative rating approach can lead to a reversal effect in the perception of a car's environmental friendliness. For example, a sportutility vehicle can be perceived as either environmentally friendly or not, depending on the type of rating approach used. The authors demonstrate that visual representation drives this effect, using a colored alphabetical rating scale to communicate environmental performance.
\end{abstract}

Keywords: choice architecture, ecolabeling, passenger cars, environmental policy, consumer information 
Labels are used to provide information to consumers, with the intent of helping them make better decisions, such as choosing more healthful foods or environmentally friendly products (Bettman, Payne, and Staelin 1986; Sprott, Hardesty, and Miyazaki 1998). However, the content and design of labels vary widely, and the means by which labels convey information can significantly influence consumer preferences and decision making (Johnson, Payne, and Bettman 1988). For example, Camilleri and Larrick (2014) demonstrate that a preference for fuel-efficient vehicles increases when a label provides fuel consumption estimates in dollar cost terms, over a long (vs. short) period of use. However, an understudied dimension of labeling, particularly in the transportation domain, involves the use of either an absolute or a relative rating approach. Under an absolute, or across-class, approach, performance of a vehicle is compared with that of all other vehicles on the market. Under a relative, or within-class, approach, the energy consumption or the environmental performance is compared only with that of other similar vehicles on the market. The choice of the referent base can affect consumer perceptions of environmental performance. For example, communicating the energy consumption of a sport-utility vehicle in absolute terms may make it appear relatively inefficient, while communicating it in relative terms can create the perception of a relatively efficient vehicle.

The simplicity of the absolute rating approach has made it the preferred approach in many countries around the world, including the United States, the United Kingdom, and France. Conversely, the opportunity to recognize relative performance in a particular class of vehicle has led to the adoption of a relative approach in countries such as Germany and Brazil. The current research's purpose is to examine how absolute and relative rating approaches influence consumers' perceptions of vehicles' environmental friendliness. We examine these approaches through the lens of choice architecture and demonstrate that a relative rating approach can lead to a reversal effect, in which consumers perceive relatively nonecofriendly products as highly 
environmentally friendly, and vice versa. The research further demonstrates that these effects are driven by the bias created through the application of a visual that makes use of a colored rating scale to communicate a vehicle's environmental performance.

This research makes several contributions to the marketing and public policy literature streams. First, it provides insight into the impact of the two (absolute vs. relative) rating approaches, used globally, by examining their efficacy. Thus, we complement previous research that examines labeling effectiveness (e.g., Camilleri and Larrick 2014; Heinzle and Wüstenhagen 2012). In doing so, we extend previous research in the field of household appliances (e.g., Waechter, Sütterlin, and Siegrist 2015) to the transport field. This is important for several reasons. As Camilleri and Larrick (2014) argue, vehicles are relatively rare purchases and thus purchased in a unique decision-making context. They also note that vehicle purchase involves significant risk for consumers, given the extreme variability of fuel prices over time. In addition, consumers are not familiar with exactly how much electricity they consume (Yamamoto et al. 2008). Thus, they have difficulty putting energy consumption figures of household appliances (e.g., kilowatt-hours) into context (Heinzle 2012). Consumers under these conditions tend to overrely on energy efficiency rating information, while largely ignoring information about actual electricity consumption (Waechter, Sütterlin, and Siegrist 2015). However, research in the transport field indicates that car drivers are more familiar with fuel prices (Civic Consulting 2014). Our research offers insights into how consumers rely on different forms of performance information in environments in which knowledge of fuel prices could help them put fuelefficiency figures into perspective.

Second, we extend previous research on "choice architecture," contributing particularly to research investigating the reversal effects of nudging intended to aid consumers' decision making. Choice architecture includes the design, organization, and structuring of how 
information and options are presented to decision makers, which can affect what information is examined, what is ignored, and how different attributes are weighted during the decision-making process (Camilleri and Larrick 2014; Johnson et al. 2012). Behavioral responses to some informational strategies sometimes lead to unintended consequences, or so-called reversal effects, with an opposite effect than intended. For example, Steinhart, Carmon, and Trope (2013) find that warnings for drug side effects could have an unintended positive effect on perceptions of the drug and subsequently increase demand. Within the context of energy consumption, Heinzle (2012) demonstrates that preferences for energy-efficient appliances actually decrease when information on energy consumption is presented in annual operating cost estimates rather than in physical unit watts. The current study demonstrates that a vehicle ecolabel system following a relative rating approach can lead to biased perceptions that high-emitting vehicles are actually more environmentally friendly than low-emitting vehicles. An examination of the impact of absolute versus relative rating approaches, and specifically within a transport context, extends the scarce literature on the reversal effects of nudging.

Third, we provide guidance to marketers and public policy officials working to encourage environmentally friendly consumer choices. The research focuses on the automotive industry because, as mentioned previously, both absolute and relative rating approaches are used globally. In addition, passenger vehicle transport is a primary source of carbon emissions; more precisely, transport is accountable for approximately one-quarter of worldwide carbon dioxide $\left(\mathrm{CO}_{2}\right)$ emissions, with road transport being responsible for $75 \%$ of this figure (International Energy Agency 2009). Marketers and policy makers have responded by setting ambitious goals to improve vehicles' environmental friendliness. Energy labels facilitate manufacturers' competitive advantage gained through the production of environmentally friendly products (Thøgersen 2000) 
and therefore act as an especially effective element in any government's portfolio of climate and energy policies (Wiel and McMahon 2005).

\section{Impact of Labeling on Consumer Behavior}

Research examining labeling is extensive, most notably in the nutrition domain. In general, this research stream demonstrates the effectiveness of graphics, recognized health symbols, adjective labels, and traffic light rating scales in positively influencing consumer choices, such as lower fat or lower sodium options (Feunekes et al. 2008; Geiger et al. 1991; Jones and Richardson 2007; Levy, Fein, and Schucker 1996). The use of such techniques often results in more accurate nutrient judgments of unhealthful food (Burton, Biswas, and Netemeyer 1994). Research also demonstrates that summary information facilitates comparisons with other brands, making the processing of nutritional labels easier (Viswanathan, Hastak, and Gau 2009). However, research also demonstrates that consumers, particularly the elderly, experience difficulty in applying quantitative values, for example, percent of daily value (Barone et al. 1996; Block and Peracchio 2006).

Numerous researchers within the domain of energy consumption have examined how altering a label's elements, such as the scale or metric used to express consumption, affects consumer decision making (e.g., Anderson and Claxton 1982; Camilleri and Larrick 2014; Deutsch 2010; Heinzle 2012; Hutton and Wilkie 1980; Kaenzig and Wüstenhagen 2010; McNeill and Wilkie 1979). For example, several researchers have investigated the use of rating scales commonly used on energy labels, illustrating that meaning of the scale levels can be changed by using scales such as $\mathrm{A}+++, \mathrm{A}++$, or $\mathrm{A}+$ versus $\mathrm{A}, \mathrm{B}$, or $\mathrm{C}$ (Heinzle and Wüstenhagen 2012; Meissner, Heinzle, and Decker 2013; Ölander and Thøgersen 2014; Waechter et al. 2016). 
Germane to the current research, Johnson, Payne, and Bettman (1988) demonstrate that increasing the amount of information consumers receive can have little impact and even result in reversal effects that lead to poorer consumer decision making. For example, Brucks, Mitchell, and Staelin (1984) find that too much nutritional information can keep consumers from integrating this information in their decision making. In contrast, overly simplified information or too-generalized claims can also lead to misunderstandings (Andrews, Netemeyer, and Burton 1998; Burke, Milberg, and Moe 1997). In summary, research across multiple domains demonstrates that altering both the content in labeling and the means of conveying that content can affect consumers' decision making (Hieke and Taylor 2012). Although relative and absolute rating approaches are widely used in ecolabels worldwide, their respective impact on consumer decision making remains relatively unstudied.

\section{Relative or Absolute Performance?}

Ecolabels often use visuals to convey a vehicle's environmental performance in an effort to better convey information. For example, the United States uses a linear fuel economy and greenhouse rating scale that displays the lowest (1) and highest (10) rating for cars available on the market and classifies the specific model under consideration within that scale. In contrast, New Zealand and Korea use a dial label format that displays a clock shape, in which advancement along the clock corresponds to higher ratings. Most other countries use vehicle labels with a bar/pyramid format with an alphabetical grading system ranging from A to G. Appendix A displays vehicle ecolabels used in several countries.

Many countries follow an absolute rating approach that compares a vehicle's environmental performance with that of the entire range of available cars on the market. Conversely, a relative rating approach classifies vehicles along a scale that considers additional 
factors such as a vehicle's type, size, and weight. A vehicle can receive the highest rating in such a system if it is among the most environmentally friendly in relation to its weight, even if its absolute fuel consumption values are high. For example, in Germany, which uses a relative rating approach, the BMW X6 xDrive 40d, a vehicle that weighs 2.18 tons and emits $163 \mathrm{~g} \mathrm{CO}_{2}$ per kilometer $(\mathrm{km})$, receives an A-rating, whereas a small Smart fortwo cabrio, a vehicle that weighs only .88 tons and emits $115 \mathrm{~g} \mathrm{CO}_{2}$ per km, receives an E-rating (DAT 2015).

According to Gärtner (2005), an absolute rating approach allows consumers to easily compare options because of its simplicity. This system requires neither explanations of the basis for categorizing vehicles nor complex calculations. It appears that absolute rating approaches are also in consonance with consumers' expectations. Even in Germany, a country using the relative approach, $69 \%$ of consumers expect that a vehicle with the highest rating should be among the vehicles with the lowest overall level of fuel consumption (Dünnhoff, Negatsch, and Strüh 2013). However, relative rating approaches offer potential advantages. Consumers often only consider vehicles in a specific vehicle class, for example, midsized, when making purchase decisions. Critics of the absolute rating approach claim that finding a more fuel-efficient model in one vehicle category would be difficult because, for example, all large vehicles — due to a higher overall level of fuel consumption than smaller vehicles-would end up in the bottom rating classes of the A-G rating scale. Consistent with the notion of the "starting problem" and diminishing sensitivity (Heath, Larrick, and Wu 1999), people are likely to be insensitive to seemingly trivial improvements in $\mathrm{CO}_{2}$ ratings. For example, motivation to invest time and money in finding a vehicle with lower fuel consumption in the same category will be reduced if the differences between options are limited to the lower rating categories. Although both approaches are used extensively worldwide, in a wide variety of decision-making domains, comparatively little research exists regarding the influence of different rating approaches on 
consumers' judgments and decision making (e.g., Codagnone, Bogliacino, and Veltri 2013; Dünnhoff, Negatsch, and Strüh 2013; Waechter, Sütterlin, and Siegrist 2015).

Research in social psychology provides further evidence of the efficacy of absolute and relative approaches in the context of people's self-ratings and the ratings of others (e.g., Goffin and Olson 2011). Within this domain, research suggests that social comparison is a natural process for various social problems and has proved beneficial for the evolution of humans in a variety of areas, including mate choice, status, self-protection, or relationship maintenance. One of the important mechanics explaining the advantages of and the human tendency to rely on comparative judgments (i.e., relative rather than absolute judgments) is that these judgments "reduce error variance by increasing [people's] agreement about the meaning of scale points" (Goffin and Olson 2011, p. 53); thus, people establish "shared reference points.” However, while research in this domain has examined the use of absolute and relative ratings, it is bound to conditions of "when people (not things) are being rated" (Goffin and Olson 2011, p. 56). Our research expands this debate by examining the impact of both approaches on consumers' decision making in a vehicle ecolabel context.

Within the domain of energy consumption, to our knowledge the only investigation of relative rating approaches has been the examination of household appliances by Waechter and colleagues (2015a; 2015b). They demonstrate that when consumers evaluate an appliance's environmental friendliness, they primarily consider the efficiency rating, which is a measurement of how efficiently an appliance uses energy relative to its size, and largely ignore information about actual electricity consumption information. This effect leads consumers to recommend products with higher levels of energy consumption. 


\section{Choice Architecture and Nudging}

Individual judgment and decision making never occur in isolation, but in a broader context that can be susceptible to manipulation, often referred to as choice architecture (Camilleri and Larrick 2014; Thaler and Sunstein 2008). Thus, the optimal design of a choice architecture is an important, challenging process in which choice architects "have the capability to self-consciously construct nudges in an attempt to move people in directions that will make their lives better" (Thaler, Sunstein, and Balz 2013, p. 430). Thaler and Sunstein $(2008$, p. 6) define these nudges as “any aspect of the choice architecture that alters people's behavior in a predictable way without forbidding any options or significantly changing their economics incentives.” Examples of such nudges include the use of reminders, warnings, visuals, defaults, informational tools, feedback, and other means by which marketers and policy makers can influence choice in accordance with a preferred option.

Employing joint multiple nudge techniques is possible within a choice architecture, in which a distinction is made based on the cognitive mechanism by which such nudges operate (Jung and Mellers 2016). Decision makers commonly apply a repertoire of strategies, ranging from carefully analyzing all information and options to applying quick mental shortcuts, also referred to as heuristics or rules of thumb (Payne, Bettman, and Johnson 1993). Sunstein (2015) argues that some nudges, such as disclosure strategies, provide consumers with facts that enhance the role of deliberation and the considered judgments. For example, informational nudges such as calorie labels raise consumers' awareness so that they become more thoughtful about their decisions (Jung and Mellers 2016). In contrast, "heuristics-triggering" nudges exploit various cognitive shortcuts, which in turn can significantly affect behavior by targeting intuitive and automatic perceptions without the involvement of active deliberation (e.g., Barton and GrüneYanoff 2015; Jung and Mellers 2016; Michalek et al. 2015). An example of such a heuristics- 
triggering nudge is the alteration of the size of a food container (e.g., plate, bowl). Perceptual illusions can help reduce the amount of food people serve themselves (e.g., Kallbekken and Sælen 2013; Van Ittersum and Wansink 2012; Wansink, Van Ittersum, and Painter 2006).

The distinction between different types of nudges is often unclear because many information-based nudges combine these dual characteristics by providing facts while trying to trigger the use of certain heuristics (Barton and Grüne-Yanoff 2015). An example of this type of nudge is the Ambient Orb, a device in the form of a small ball that provides information on realtime energy consumption, glowing red during high levels and green during acceptable levels (Maan et al. 2011). The energy-feedback device provides factual information about the energy consumption level, but the use of color also triggers an unconscious reaction to conserve energy (Maan et al. 2011; Michalek et al. 2015; Selinger and Whyte 2011). Color typically affects people automatically, without conscious awareness (Elliot and Maier 2014). For example, red is often unconsciously negatively associated with concepts such as risk, danger, red traffic lights, a schoolteacher's red pen to correct mistakes, or warning signals (Michalek et al. 2015; Selinger and Whyte 2011). In contrast, green is often associated with positive content, including success (Moller, Elliot, and Maier 2009).

Previous research suggests that nudges triggering cognitive shortcuts can be more effective than factual, numeric-based information (Jung and Mellers 2016; Roberto and Kawachi 2014; Wisdom, Downs, and Loewenstein 2010). For example, a study investigating the impact of traffic light labels in a hospital, in which automatic associations are triggered between "red" and "stop" for unhealthful food and "green" and "go" for more healthful food (Liu et al. 2014), reveals that this labeling system increases consumer preference for "green-light" items sold in a cafeteria (Thorndike et al. 2014). This finding implies that this approach might act as a more effective nudging tool than a more numeric-based nutritional information approach (Roberto and 
Kawachi 2014). Apart from triggering unconscious associations, the use of color can increase the salience of specific pieces of information. Information that is made more salient with bright colors or sharp contrasts, for example, is significantly more likely to be used in the decisionmaking process (Jarvenpaa 1990; Lurie and Mason 2007; Sunstein 2014). Taylor (1982) calls this the salience bias, stating that colorful, dynamic, or other distinctive stimuli trigger attention and therefore affect the decision-making process.

In addition to color, techniques such as traffic light frameworks are effective because they map informational content on an evaluative (good/bad) scale. Previous research indicates that people tend to undervalue information that is abstract and statistical (e.g., Kahneman and Tversky 1973; Nisbett and Ross 1980). The use of categories with clear end points, such as grades, reduces cognitive effort, making information evaluation easier (Johnson et al. 2012; Peters et al. 2009). The less cognitive effort needed, the more the information weighs during the decisionmaking process (Peters et al. 2007).

\section{Choice Architecture and Ecolabels}

The choice architecture of vehicle ecolabels includes different elements. On the one hand, factual numerical information is commonly included to help consumers directly compare cars' fuel and environmental performance. On the other hand, many vehicles' ecolabels also include vivid visuals, in the form of a colored alphabetical rating scale, or the "pyramid visual." The use of such a visual aims to lower cognitive effort, which triggers the use of cognitive shortcuts, due to color priming, increased salience, and increased evaluative meaning of the provided information.

We argue that using the pyramid visual will lead people to predominantly focus on rating information in environmental judgments, regardless of whether the ecolabel follows an absolute or relative rating approach. Thus, we assume that the amount of processing effort in evaluating a 
car's environmental friendliness, based on the given information, should not differ between various rating approach conditions. Therefore, the dominance of the rating information should result in a reversal effect under the relative rating approach, in which relative comparisons can lead to misperceptions that high-emitting vehicles are actually more environmentally friendly than low-emitting vehicles. Specifically, we propose that the use of a relative rating approach leads to a reversal effect in consumers' perceptions of vehicles' environmental friendliness:

$\mathbf{H}_{1}$ : Participants will rate the environmental friendliness of a high-emitting vehicle as higher (lower) compared to a low-emitting vehicle when a relative (absolute) approach to eco-labeling is used.

Moreover, when processing information with difficulty or disfluently, people perceive this as a cue that their intuitive, fast response might be erroneous (Alter et al. 2007). This, in turn, should stimulate reconsideration (Amir and Lobel 2008), leading consumers to integrate more information into their judgments. Thus, the deliberation process should be longer when possible label inconsistencies are explicitly highlighted, for example, by drawing consumers' attention to a car's low fuel and environmental performance if it scores highly along a relative rating scale. We hypothesize:

$\mathbf{H}_{2 \mathbf{a}}$ : Participants spend more time on evaluating a car's environmental friendliness when inconsistent environmental performance information is provided.

We subsequently hypothesize that such inconsistent nudges can correct for the hypothesized reversal bias:

$\mathbf{H}_{2 \mathbf{b}}$ : Due to the provision of conflicting information, participants will not rate the environmental friendliness of a high-emitting vehicle as higher compared to a lowemitting vehicle when a relative approach to eco-labeling is used. 


\section{Study 1}

In study 1, we investigate whether the use of a relative rating approach with ecolabels can lead to a reversal effect in consumers' perceptions of vehicles' environmental friendliness in such a way that consumers perceive high-emitting vehicles as more environmentally friendly than their more environmentally friendly, low-emitting counterparts.

\section{Method}

\section{Participants}

Participants in Study 1 were 125 graduate students and recent graduates of a graduate program in International Management (CEMS) from several countries in Europe. To secure participants, the link to the survey was posted in the CEMS worldwide Facebook group, which hosted more than 3500 members at the time of the survey, as well as in local university CEMS Facebook groups. As an incentive to motivate survey participation, a lottery was announced in which every participant completing the survey had the chance of winning a gift card. Table 1 provides a description of the sample composition for all studies.

Insert table 1 here

\section{Procedure}

Study 1 was a 2 (vehicle type: low-emitting, high-emitting) $\times 2$ (rating approach: absolute, relative) between-subjects design. We randomly assigned participants to one experimental labeling condition. Before presentation of one of the four label versions (see Figure 1 for the labels used in this study), we informed participants that an ecolabel that included information on the level of $\mathrm{CO}_{2}$ emissions, level of fuel consumption of a specific car model, and the environmental performance of the car based on an alphabetical grading system ranging from A to 
G would be presented to them subsequently. On continuing the survey via a mouse click, study participants then saw one of the four respective labels as displayed in Figure 1 in random order. On the same page, participants were asked to evaluate the environmental friendliness of that specific car model with the information provided. The label for a low-emitting vehicle presented participants with an A-rating in the absolute rating condition and a D-rating in the relative rating condition. Similarly, the label for the high-emitting vehicle presented a D-rating in the absolute rating condition and an A-rating in the relative rating condition. This latter condition reflects the reality of a relative rating approach, in which a high-emitting vehicle can still receive a high rating because of its standing relative to other vehicles in the same class. The size of the information regarding the calculation basis paralleled how this information is displayed on most vehicle ecolabels used worldwide, as shown in Appendix A.

Insert figure 1 here

\section{Measures}

The dependent variable for this study was the perception of the car's environmental friendliness rated on a Likert scale ( 1 = "extremely eco-unfriendly," and 9 = "extremely eco-friendly"). In addition, we measured several covariates, displayed in the Study 1 column of Table 1. A detailed description of how we measured the covariates is available in Table 2.

\section{Results and Discussion}

An analysis of covariance (ANCOVA) revealed significant individual main effects for the vehicle type $\left(\mathrm{F}(1,114)=7.23, p=.01, \eta_{\mathrm{p}}^{2}=.06\right)$ but not for the rating approach $(\mathrm{F}(1,114)=.01, p=.92$, 
$\left.\eta_{\mathrm{p}}^{2}<.001\right)$. However, a significant interaction emerged $\left(\mathrm{F}(1,114)=49.05, p<.001, \eta p^{2}=.30\right)$. Participants under the absolute rating approach conditions perceived the low-emitting vehicle's environmental friendliness as much higher than that of the high-emitting vehicle $\left(\mathrm{M}_{\mathrm{low} / \mathrm{abs}}=7.32\right.$, $\left.\mathrm{SD}=1.87 \mathrm{vs} . \mathrm{M}_{\mathrm{high} / \mathrm{abs}}=4.39, \mathrm{SD}=1.33 ; \mathrm{t}(60)=7.12, p<.001\right)$. In contrast, they perceived the environmental friendliness of the low-emitting vehicle as lower than that of the high-emitting vehicle under the relative rating approach conditions $\left(\mathrm{M}_{\text {low/rel }}=5.00, \mathrm{SD}=1.91 \mathrm{vs} . \mathrm{M}_{\mathrm{high} / \mathrm{rel}}=\right.$ $6.56, \mathrm{SD}=1.97 ; \mathrm{t}(61)=3.19, p<.01$; see Figure 2$)$. In addition, we introduced all variables included in the Study 1 column of Table 1 as covariates. However, none of the covariates were significantly related to the evaluation of the two vehicle types' environmental friendliness. These findings provide initial support for $\mathrm{H}_{1}$ and demonstrate that under a relative rating approach, consumers perceive high-emitting vehicles as more environmentally friendly than their more environmentally friendly, low-emitting counterparts. These results confirm the presence of a choice architecture-driven bias, leading to a reversal effect, in which consumers rate a lowemitting vehicle as less environmentally friendly than a vehicle with high emissions levels. However, we acknowledge that the identified reversal effect might follow from the specific sample surveyed (i.e. students) as well as from the set-up of our experiment, which required respondents to infer the environmental friendliness from the display of an eco-label solely without seeing the actual vehicle. In order to ensure a higher generalizability of the results, we conduct a follow-up study 2 .

Insert figure 2 here

\section{Study 2}


Study 2 replicates and extends Study 1 in three important ways. First, we use a more generalizable nonstudent sample. Second, to enhance realism, we use two actual vehicles as the basis for the ecolabels. Third, the response time consumers spent in each rating approach condition on evaluating the ecolabel — that is, the time between the information's presentation and the response (Bettman, Johnson, and Payne 1991) - serves as an indirect measure of the amount of processing effort in evaluating a car's environmental friendliness. This confirms the prediction that consumers' overemphasis on rating information drives the findings from Study 1, regardless of whether the ecolabel follows an absolute or relative rating approach.

\section{Method}

\section{Participants}

Participants in Study 2 were 151 car drivers from Germany, who were recruited from a German online access panel maintained by the market research company Consumerfieldwork GmbH, an international consumer panel company with more than 50,000 consumers across Germany. Participants were compensated by the panel company for taking part in the study. We randomly chose participants from the German panel and allowed them to participate in the study if they owned a driver's license.

\section{Procedure}

Study 2 used the same procedure and $2 \times 2$ between-subjects design as in Study 1, with one important addition. We used ecolabel information and vehicle photographs for two vehicles currently on the market - the Citroen $\mathrm{C} 1$, rated at $4.3 \mathrm{~L} / 100 \mathrm{~km}$ and $99 \mathrm{~g} \mathrm{CO}_{2} / \mathrm{km}$, and the Lexus $\mathrm{RX} 450 \mathrm{~h}$, rated at $6.3 \mathrm{~L} / 100 \mathrm{~km}$ and $145 \mathrm{~g} \mathrm{CO}_{2} / \mathrm{km}$ (see Figure 3). After viewing the ecolabel and the vehicle photographs, participants rated the environmental friendliness of the vehicle using the same measure as in Study 1. In addition, we measured several covariates displayed in the Study 2 
column of Table 1. Finally, to indirectly measure the amount of processing effort, we recorded the amount of time in seconds that participants spent on the survey page on which they were presented with the label and vehicle photographs and asked to evaluate the environmental friendliness of the vehicle.

Insert figure 3 here

\section{Results and Discussion}

An ANCOVA revealed a significant main effect for the vehicle type $(\mathrm{F}(1,139)=6.89, p=.01$, $\left.\eta_{\mathrm{p}}^{2}=.05\right)$ but not for the rating approach $\left(\mathrm{F}(1,139)=.50, p=.48, \eta_{\mathrm{p}}^{2}=.004\right)$. A significant interaction between vehicle type and rating approach emerged $\left(\mathrm{F}(1,139)=139.00, p<.001, \eta p^{2}\right.$ $=.50)$. In addition, all variables included in the Study 2 column of Table 1 served as covariates. The covariates "A-G rating knowledge" $\left(\mathrm{F}(1,139)=4.38, p=.04, \eta p^{2}=.03\right)$ and "importance of environmental issues" $\left(\mathrm{F}(1,139)=4.86, p=.03, \eta p^{2}=.03\right)$ were significantly related to the evaluation of the vehicle's environmental friendliness.

Similar to Study 1 , and providing further support for $\mathrm{H}_{1}$, simple effects analyses revealed that participants perceived the environmental friendliness of the low-emitting vehicle as significantly higher than that of the high-emitting vehicle under the absolute rating approach condition $\left(\mathrm{M}_{\mathrm{low} / \mathrm{abs}}=7.78, \mathrm{SD}=1.27\right.$ vs. $\left.\mathrm{M}_{\text {high/abs }}=4.38, \mathrm{SD}=1.41 ; \mathrm{t}(77)=11.19, p<.001\right)$. Conversely, participants perceived the environmental friendliness of the low-emitting vehicle as lower than that of the high-emitting vehicle under the relative rating approach condition $\left(\mathrm{M}_{\text {low/rel }}\right.$ $=5.26, \mathrm{SD}=1.43$ vs. $\mathrm{M}_{\text {high/rel }}=7.34, \mathrm{SD}=1.56 ; \mathrm{t}(70)=5.85, p<.001$; see Figure 4). 
Insert figure 4 here

The median response time was 23 seconds for participants of treatment group 1 (low/abs), 24.5 seconds for participants in treatment group 2 (high/abs), 26 seconds for participants of treatment group 3 (low/rel) and 25 seconds for participants of treatment group 4 (high/rel). Given that the data distribution violated the assumption of normality, we conducted a Kruskal Wallis H test, which showed that participants' response time did not differ between the four treatment groups $\left(\chi^{2}(3)=2.09, p=.55\right)$ with a mean rank of 67.09 for participants of treatment group 1, 77.71 for participants of treatment group 2, 79.27 for participants of treatment group 3 and 80.03 for participants of treatment group 4. In other words, participants did not spend significantly more time on evaluating a car's environmental friendliness under the different labeling conditions. Rather, it seems that participants applied a shortcut using the pyramid visual to quickly process information, neglecting other important data and misinterpreting the relative information from high-emitting vehicles. This finding suggests that the reversal effect from a relative labeling approach is driven by a reliance on visual cues. Next, in study 3, we investigate whether a label design that includes a relative rating scale that gives greater prominence to the fuel mileage metric of both vehicles types, through embedded color-coded information, attenuates the identified reversal effect.

\section{Study 3}

Furthermore, Study 3 extends Studies 1 and 2 in three other important ways. First, we examine the efficacy of absolute and relative rating approaches in a different market, the United States, in which consumers are not predisposed to a label design that makes use of the pyramid visual. Second, because the vehicles from the previous studies are not available for sale to consumers in 
the United States, we provide generic class descriptions instead of actual vehicles. Third, we use a three-item measure of environmental friendliness to enhance the robustness of the previous studies' findings.

\section{Method}

\section{Participants}

Participants in Study 3 were 162 business students from a southeastern university in the United States. All earned extra credit in exchange for taking part in the study.

\section{Procedure}

Similar to the previous studies, we asked participants to evaluate the environmental friendliness of a specific vehicle after being presented with an ecolabel. In contrast with Studies 1 and 2, we first asked participants to examine the label shown in the respective experimental conditions as displayed in Figure 5. Participants could freely decide to end exposure to the label and continue with the survey via a mouse click. We used this exposure time (in seconds) as the indirect measure of the amount of processing effort in evaluating a car's environmental friendliness. On continuing the survey, participants then evaluated the environmental friendliness of that specific car model with the information provided.

A colored bar appeared at the bottom of each label in each labeling condition, along with the vehicle's actual fuel performance. Doing so allows us to examine whether a label design that gives more prominence to the car's absolute fuel performance can attenuate the reversal effect. For example, although in the relative rating condition the low-emitting vehicle displayed a yellow bar in the middle of the pyramid scale, the bottom of the label contained a bright green bar that reported the fuel economy. Participants were not provided with the names of vehicles, but the 
actual fuel mileage and emissions from the Ford Fiesta (low-emitting vehicle condition) and the Ford Escape (high-emitting vehicle condition) were used (see Figure 5 for the labels).

Insert figure 5 here

We measured perceived environmental friendliness using a three-item, nine-point scale ( $\alpha$ $=.91)$ : "Based on the available information, how environmentally friendly would you consider this particular car to be?" (extremely environmentally damaging/extremely environmentally friendly); "If you had a friend in the market for a car who is concerned about the environment, how likely would you be to recommend this car to your friend?" (extremely unlikely/extremely likely); and "If one of your neighbors were buying this car, how environmentally conscious would you consider this person to be?" (extremely environmentally unconscious/extremely environmentally conscious). We also collected the same set of covariates as in the previous studies (see Study 3 column in Table 1), as well as a measure of the importance ascribed to information from labels and the perceived credibility of that information (Teisl, Rubin, and Noblet 2008).

\section{Results and Discussion}

An ANCOVA reveals no significant individual main effects for either vehicle type $(\mathrm{F}(1,147)=$ $\left.1.51, p=.22, \eta p^{2}=.01\right)$ or the rating approach type $\left(\mathrm{F}(1,147)=.18, p=.67, \eta p^{2}<.001\right)$.

However, a significant interaction between vehicle type and rating approach type emerged $(\mathrm{F}(1$, $\left.147)=56.44, p<.001, \eta p^{2}=.28\right)$. Participants perceived the low-emitting vehicle's environmental friendliness as significantly higher than the high-emitting vehicle's environmental friendliness under the absolute rating conditions $\left(\mathrm{M}_{\text {low/abs }}=6.99, \mathrm{SD}=1.38 \mathrm{vs} . \mathrm{M}_{\mathrm{high} / \mathrm{abs}}=4.83\right.$, 
$\mathrm{SD}=1.03 ; \mathrm{t}(79)=8.01, p<.001)$. Conversely, participants still perceived the high-emitting vehicle as superior in environmental performance to that of the low-emitting vehicle under the relative rating conditions $\left(\mathrm{M}_{\mathrm{low} / \mathrm{rel}}=5.30, \mathrm{SD}=1.40\right.$ vs. $\mathrm{M}_{\text {high/rel }}=6.68, \mathrm{SD}=1.70 ; \mathrm{t}(79)=4.01, p$ $<.001$; see Figure 6). In addition, all variables included in the Study 3 column of Table 1 served as covariates, but none reached significance.

Insert figure 6 here

Finally, the median exposure time was 14 seconds for participants of treatment group 1 (low/abs), 15.5 seconds for participants in treatment group 2 (high/abs), 18.5 seconds for participants of treatment group 3 (low/rel) and 15 seconds for participants of treatment group 4 (high/rel). A Kruskal Wallis $\mathrm{H}$ test indicated that the time spent evaluating the ecolabel did not differ between the four treatment groups $\left(\chi^{2}(3)=3.148, p=.37\right)$, with a mean rank of 74.00 for participants of treatment group 1, 81.28 for participants of treatment group 2, 91.62 for participants of treatment group 3 and 78.72 for participants of treatment group 4. Participants did not spend more time evaluating the vehicle's environmental friendliness when they were provided with conflicting information (e.g., the low-emitting vehicle with a yellow "D" rating on the pyramid and fuel mileage highlighted with a green background color). Therefore, Study 3 replicates previous findings that the use of a visual pyramid to communicate a vehicle's environmental performance is highly salient, leading consumers to neglect other important data, even when fuel consumption figures are embedded in color codes. The use of the strong visual evidently dominates consumers' information processing, even under conditions in which apparently conflicting information is provided. The use of a visual impairs consumers' ability to consider other information that would provide information on the car's absolute fuel 
performance. Therefore, the findings from Study 3 do not provide support for $\mathrm{H}_{2 \mathrm{a}}$ and $\mathrm{H}_{2 \mathrm{~b}}$. Given the importance of the visual display in labeling, in Study 4 we examine whether increasing the visual dominance of the conflicting information affects consumer processing time and the reversal effect.

\section{Study 4}

The objective of Study 4, given the tendency for consumers to erroneously perceive environmental friendliness under a relative rating approach, is to examine another potential means of attenuating the identified reversal effect. We do so by including additional absolute environmental performance information under an ecolabel following a relative rating approach. Demonstrating the efficacy of such an approach would allow marketers and public policy makers to take advantage of the benefits of a relative approach while correcting for consumers' bias. This approach is currently being used in Switzerland (Swiss Federal Office of Energy 2015).

\section{Method}

\section{Participants}

Participants in Study 4 were 151 car drivers from Germany, who were recruited from the same German online access panel by the market research company Consumerfieldwork $\mathrm{GmbH}$ as in Study 2. Study participants were compensated by the panel company for taking part in the study. As in Study 2, we randomly chose participants from the German panel and allowed them to participate in the study if they owned a driver's license.

\section{Procedure}


We used the same labels from Study 2 in Study 4 for the two labeling conditions following the absolute rating approach. The labels following a relative rating approach in Study 4 were similar to those used in Study 2 but contained additional information informing participants of the vehicle's performance compared with that of other vehicles overall (see Figure 7). Through the introduction of this conflicting information, we aimed to investigate whether the use of such additional information corrects for the identified reversal effect from the previous studies. We measured environmental performance with the same items as in Study 2. Finally, as with Study 2 we recorded the amount of time in seconds that participants spent on the survey page on which they were presented with the label and vehicle photographs and asked to evaluate the environmental friendliness of the vehicle. Finally, we measured the same covariates as in Study 2.

Insert figure 7 here

\section{Results and Discussion}

An ANCOVA revealed a significant main effect for the vehicle type $(\mathrm{F}(1,139)=26.34, p<.001$, $\left.\eta p^{2}=.16\right)$ but not for the rating approach $\left(\mathrm{F}(1,139)=.32, p=.57, \eta p^{2}=.002\right)$. However, a significant interaction again emerged between vehicle type and rating approach type $(\mathrm{F}(1,139)=$ $\left.52.78, p<.001, \eta p^{2}=.28\right)$. Additional analysis revealed that participants perceived the environmental friendliness of the low-emitting vehicle as significantly higher than that of the high-emitting vehicle under the absolute rating conditions $\left(\mathrm{M}_{\text {low } / \mathrm{abs}}=7.78, \mathrm{SD}=1.27 \mathrm{vs} . \mathrm{M}_{\text {high/abs }}\right.$ $=4.38, \mathrm{SD}=1.41 ; \mathrm{t}(77)=11.19, p<.001)$. Conversely, participants perceived the environmental friendliness of the high-emitting vehicle as similar to that of the low-emitting vehicle under the 
relative rating conditions $\left(\mathrm{M}_{\text {low/rel }}=5.56, \mathrm{SD}=1.60 \mathrm{vs} . \mathrm{M}_{\text {high/rel }}=6.24, \mathrm{SD}=1.85 ; \mathrm{t}(70)=1.61, p\right.$ $=.11$; see Figure 8 ). None of the covariates reached significance.

Insert figure 8 here

Finally, the median response time was 23.5 seconds for participants of treatment group 1 (low/abs), 24.5 seconds for participants in treatment group 2 (high/abs), 30 seconds for participants of treatment group 3 (low/rel) and 29 seconds for participants of treatment group 4 (high/rel). A Kruskal Wallis $\mathrm{H}$ test showed that the time evaluating the ecolabel, in contrast with Study 3, differed between the four treatment groups $\left(\chi^{2}(3)=13.23, p<.01\right)$, with a mean rank of 59.37 for participants of treatment group 1, 69.99 for participants of treatment group 2, 85.06 for participants of treatment group 3 and 91.91 for participants of treatment group 4. A MannWhitney U-test revealed that the two treatment groups that were presented with an ecolabel making use of the relative rating approach in combination with the additional information at the bottom of the label took more time to answer the question related to the perception of the environmental performance of cars than the two groups that were presented with ecolabels displaying solely a rating scale based on the absolute rating approach $(\mathrm{U}=1955.50, \mathrm{Z}=3.41, p<$ .001). This explains why the use of the additional horizontal rating scale could reduce the reversal effect to some extent. Nevertheless, participants' perceptions that the low-emitting vehicle had similar environmental performance to that of the high-emitting vehicle prove that misperceptions still persist. In summary, Study 4 provides partial support for $\mathrm{H}_{2 \mathrm{a}}$ and $\mathrm{H}_{2 \mathrm{~b}}$. Specifically, presenting conflicting information in visual form attenuates, but does not completely eliminate, the reversal effect found in the previous studies. 
This finding is noteworthy because at least one country, Switzerland, uses the relative rating approach, with the inclusion of additional absolute environmental performance information at the bottom of the label following a relative rating approach. This additional information reduces, but does not eliminate, consumers' bias resulting in reversal effects. Thus, well-meaning public policy designed to inform consumers and encourage environmentally responsible consumption may still have deleterious effects. This finding confirms previous research on boomerang effects, showing that at times public policy interventions can produce effects opposite of those intended (e.g. Ringold 2002).

\section{General Discussion and Implications}

Choice architects can have considerable power in influencing consumers' judgments and decision making. Our research demonstrates that a poorly designed choice architecture for communicating vehicles' eco-friendliness can have significant adverse consequences. The use of a relative rating approach, in combination with a pyramid visual on ecolabels, leads to a reversal effect in consumers' perceptions of vehicle environmental friendliness. We demonstrate that such a labeling system can lead to perceptions that high-emitting vehicles are more environmentally friendly than low-emitting vehicles. Thus, the study extends previous research showing that some nudges, such as informational tools, can even result in reversal effects that lead to poorer consumer decision making.

Our series of studies demonstrate that the use of the pyramid visual to communicate environmental performance drives this effect. The pyramid visual dominates consumers' information processing, even under conditions in which apparently conflicting information is provided. Our findings confirm our prediction that the pyramid visual, due to a variety of effects, including color priming, increased salience, and evaluative meaning, exerts a stronger impact on 
people's judgments than numeric-based fuel and environmental performance information. We conclude that this visual dominance is only problematic under the relative rating approach.

\section{Key Policy Implications}

Currently, no global standard exists to guide public policy on the potential benefits of both absolute and relative rating approaches. However, some countries are taking steps to move forward. For example, in the spring of 2015, the European Commission (EU) launched an evaluation of current legislation to identify what steps could be taken to improve the efficiency of the labeling approaches used among member states. In doing so, the EU is considering the introduction of a European-wide applicable standardized ecolabel for cars, which should display an alphabetical rating scale, ranging from A to G. However, the primary debate remains the polarizing positions that favor either an absolute or a relative rating approach.

The absolute rating approach, based on the current research findings, is the most direct form of information regarding vehicles' environmental performance. This approach does not create consumer misperceptions of vehicles' environmental friendliness. In contrast, a vehicle ecolabel following a relative rating approach could mislead and confuse consumers, in that they could place low-emitting vehicles in lower rating classes than high-emitting vehicles.

In addition, technological advancements in recent years have allowed for much greater variance in environmental performance in a single vehicle class. Although historically vehicles in the same class have had relatively few differences, the introduction of new technologies such as hybrid cars and electric vehicles has drastically changed the landscape. Such innovative technologies have made it feasible to produce large, heavy cars with a low level of energy consumption and corresponding $\mathrm{CO}_{2}$ emissions. For example, the Mercedes S-class 500 model is available in the standard petrol version, with $\mathrm{CO}_{2}$ emissions values of $192-206 \mathrm{~g} / \mathrm{km}$, or in a 
plug-in hybrid version, with $65 \mathrm{~g} \mathrm{CO}_{2} / \mathrm{km}^{1}$ ' The global vehicle market is expected to transform significantly in the following years. Kalmbach et al. (2012) expect a 40\% powertrain electrification or hybridization of all new vehicles sold in the EU by 2025 . These figures, resulting from meaningful product innovation, create a significant variance in environmental performance between model options, which should appease critics of the relative rating approach that claim that finding a more fuel-efficient model within one vehicle category would be too difficult. Furthermore, our research suggests that public policy that favors an absolute approach will motivate manufacturers to develop more fuel-efficient fleets. Manufacturers that demonstrate technological leadership can better reap a competitive advantage with an absolute rating approach, given that such a labeling scheme will allow those companies to differentiate themselves on the basis of their vehicles' environmental performance.

The need to develop effective approaches for conveying environmental performance to consumers has become particularly salient in the wake of recent automaker emissions scandals (e.g., Volkswagen). The need to maintain consumer trust is paramount, with environmental performance and associated laboratory testing being called into question. Given that research indicates that most car buyers expect a car with the highest rating to be among the most fuelefficient cars (Dünnhoff, Negatsch, and Strüh 2013), a logic that parallels an absolute rating approach, pursuing a relative rating approach carries the potential for consumer backlash. Consumers could develop a deeper mistrust in environmental performance data if the ecolabeling system used to communicate that performance creates a reversal effect. This, in turn, could undermine the policy's overall effectiveness, as well as further deteriorate consumers' trust in the automotive industry.

\footnotetext{
1 See http://www.mercedesbenz.ch/content/switzerland/mpc/mpc_switzerland_website/de/home_mpc/passengercars/home/new_cars/models/sclass/w222/configurator/configurator_v222.html\#/p3501/.
} 
Our results also have implications for ecolabeling in other product categories. The discussion on whether to set relative or absolute rating approaches has also occurred in the context of household appliances. Similar to the current discourse on vehicle labels, the European Commission introduced its first European-wide energy-labeling system for household appliances in 1992. The central element of the label was a seven-class scale from A to G that rated products' energy efficiency. This directive has been modified several times, and was updated in 2010 with Directive 2010/30/EU, with the decision to introduce additional A categories (A+++, A++, or A+) for several product categories (Heinzle and Wüstenhagen 2012). A relative system is typically used to determine an appliance's rating, comparing its energy consumption with a specific dimension, for example, screen size for televisions and internal volume for refrigerators and freezers. Although all product categories' efficiency levels have improved in recent years, Dünnhoff, Negatsch, and Strüh (2013) argue that the positive effects of such improvements have been outpaced by the concurrent growth in the size of appliances. This effect is particularly apparent with televisions. Today's larger liquid crystal display (LCD) screens use almost as much energy as the old cathode ray tube televisions, while receiving the highest efficiency rating (Dünnhoff, Negatsch, and Strüh 2013). One explanation for this trend is that consumers mainly consider the efficiency rating and not the actual energy consumption level, which leads them to underestimate appliances' actual energy consumption and eventually buy products with higher energy consumption (Waechter, Sütterlin, and Siegrist 2015).

\section{Future Research Directions}

Our findings highlight significant potential for further research. First, research could investigate the impact of the different rating approaches on consumers' information processing in different contexts or using different measures. For example, researchers could analyze these approaches in the lab using methods such as eye-tracking or brain scanning. As this article investigates the 
impact of the rating approaches on consumers' perception of cars' environmental performance, other research could pursue how the different rating schemes affect actual consumer choices, either in a field setting or in a lab using choice experiments. In addition, research could extend our findings by investigating whether the reversal effect also occurs when several car models are presented in parallel. Analyzing several car models simultaneously might provide consumers with points of reference for more realistic judgments.

Second, further research could investigate how other information affects consumers' assessment of relative and absolute rating approaches. One of the more common heuristics consumers use is the relationship between price and quality (Rao and Monroe 1989). In the context of a vehicle purchase, consumers may perceive environmental friendliness as a dimension of product performance and thus infer differential environmental performance from a higher/lower price. Furthermore, consumer education regarding the nature and logic of the relative rating approach may limit the identified reversal effect. Research could also investigate whether consumers would still rate low-emitting vehicles as more environmentally friendly than sport-utility vehicles in the absence of the visual pyramid on the ecolabel, following a relative rating approach.

Third, as we tested only the effectiveness of two label designs, intended to eliminate reversal effects under the relative rating approach, considerable scope exists for researchers to test other ways to attenuate the identified bias. Research could also investigate ways to integrate relative performance information for an ecolabel that follows an absolute rating approach. For example, researchers could test whether "subcategories" (e.g., D1, D2) in one rating class (e.g., D) would enable consumers to recognize more nuanced differences between similar-sized cars.

Fourth, further research is also necessary to understand the impact of a rating approach on moral licensing. Several studies reveal that behaving sustainably in one energy domain might 
deter other sustainable energy behaviors in other domains, an effect known as the "negative spillover effect" or "moral licensing" (Thøgersen and Ölander 2003). Tiefenbeck et al. (2013) demonstrate that energy consumption increases after people reduce their water use. Similarly, Thøgersen and Ölander (2003) reveal that people are less likely to engage in recycling after buying organic products. Research could investigate whether the relative rating approach could lead consumers to believe that their engagement in one sustainable behavior, such as buying an environmentally friendly vehicle, subsequently legitimizes unsustainable behaviors. Furthermore, this effect could occur in both one domain (i.e., Jevons paradox) and in different domains.

Finally, this research could be extended to contexts outside labels and rating scales, to broader environmental performance communications. While environmentally friendly products were a niche market for many decades, many companies are increasingly using green claims in advertising. Many products are marketed on the basis of green attributes, even though they are only slightly greener than other options in the same product category (i.e., a relative claim). For example, the promotion of bottled water as being environmentally friendly or promoting an airline with an environmentally friendly appeal illustrates the use of relative appeals and their pitfalls. Although these product claims might be true within the relative product category, the use of such claims risks distracting consumers from the greater environmental impact of the entire category. 


\section{References}

Alter, Adam L., Daniel M. Oppenheimer, Nicholas Epley, and Rebecca N. Eyre (2007), “Overcoming Intuition: Metacognitive Difficulty Activates Analytic Reasoning,” Journal of Experimental Psychology: General, 136 (4), 569-76.

Amir, On and Orly Lobel (2008), "Stumble, Predict, Nudge: How Behavioral Economics Informs Law and Policy," Columbia Law Review, 108 (8), 2098-38.

Anderson, C. Dennis and John D. Claxton (1982), "Barriers to Consumer Choice of Energy Efficient Products," Journal of Consumer Research, 9 (2), 163-70.

Andrews, Craig J., Richard G. Netemeyer, and Scot Burton (1998), “Consumer Generalization of Nutrient Content Claims in Advertising," Journal of Marketing, 62 (4), 62-75.

Barone, Michael J., Randall L. Rose, Kenneth C. Manning, and Paul W. Miniard (1996), "Another Look at the Impact of Reference Information on Consumer Impressions of Nutrition Information,” Journal of Public Policy \& Marketing, 15 (1), 55-62.

Barton, Adrien and Till Grüne-Yanoff (2015), "From Libertarian Paternalism to Nudging — and Beyond," Review of Philosophy and Psychology, 6 (3), 341-59.

Bettman, James R., Eric J. Johnson, and John W. Payne (1991), “Consumer Decision Making,” in Handbook of Consumer Behavior, Thomas R. Robertson and Harold H. Kassarjian, eds. Englewood Cliffs, NJ: Prentice Hall, 50-84.

— John W. Payne, and Richard Staelin (1986), "Cognitive Considerations in Designing Effective Labels for Presenting Risk Information," Journal of Public Policy \& Marketing, $5,1-28$.

Block, Lauren G. and Laura A. Peracchio (2006), “The Calcium Quandary: How Consumers Use Nutrition Labels," Journal of Public Policy \& Marketing, 25 (2), 188-96. 
Brucks, Merrie, Andrew A. Mitchell, and Richard Staelin (1984), "The Effect of Nutritional Information Disclosure in Advertising: An Information Processing Approach,” Journal of Public Policy \& Marketing, 3, 1-25.

Burke, Sandra J., Sandra J. Milberg, and Wendy W. Moe (1997), “Displaying Common but Previously Neglected Health Claims on Product Labels: Understanding Competitive Advantages, Deception, and Education," Journal of Public Policy \& Marketing, 16 (2), 242-55.

Burton, Scot, Abhijit Biswas, and Richard Netemeyer (1994), "Effects of Alternative Nutrition Label Formats and Nutrition Reference Information on Consumer Perceptions, Comprehension, and Product Evaluations," Journal of Public Policy \& Marketing, 13 (1), $36-47$.

Camilleri, Adrian R. and Richard P. Larrick (2014), "Metric and Scale Design as Choice Architecture Tools," Journal of Public Policy \& Marketing, 33 (1), 108-25.

Civic Consulting (2014), "Consumer Market Study on the Functioning of the Market for Vehicle Fuels from a Consumer Perspective," (accessed April 25, 2016), [available at http://ec.europa.eu/consumers/consumer_evidence/market_studies/vehicle_fuels/docs/stud y_en.pdf/].

Codagnone, Christiano, Francesco Bogliacino, and Giuseppe Veltri (2013), “Testing $\mathrm{CO}_{2} / \mathrm{Car}$ Labelling Options and Consumer Information," (accessed April 25, 2016), [available at http://ec.europa.eu/clima/policies/transport/vehicles/labelling/docs/report_car_labelling_e n.pdf/].

DAT (2015), “Leitfaden über den Kraftstoffverbrauch, die $\mathrm{CO}_{2}$-Emissionen und den Stromverbrauch aller neuen Personenkraftwagenmodelle, die in Deutschland zum 
Verkauf angeboten werden," (accessed November 26, 2015), [available at http://www.pkw-label.de/uploads/media/DAT201504.pdf/].

Deutsch, Matthias (2010), "Life Cycle Cost Disclosure, Consumer Behavior, and Business Implications," Journal of Industrial Ecology, 14 (1), 103-20.

Dünnhoff, Elke, Katrin Negatsch, and Carmen Strüh (2013), “Energieverbrauchskennzeichnung von elektrischen Geräten - Ergebnisse des zweiten Marktchecks im Dezember 2012 und einer Verbraucherbefragung," (accessed April 25, 2016), [available at http://www.verbraucherzentrale-rlp.de/media222477A/].

Elliot, Andrew J. and Markus A. Maier (2014), "Color Psychology: Effects of Perceiving Color on Psychological Functioning in Humans," Annual Review of Psychology, 65, 95-120.

Feunekes, Gerda I., Ilse A. Gortemaker, Astrid A. Willems, René Lion, and Marcelle Van Den Kommer (2008), "Front-of-Pack Nutrition Labelling: Testing Effectiveness of Different Nutrition Labelling Formats Front-of-Pack in Four European Countries,” Appetite, 50 (1), $57-70$.

Gärtner, Andrea (2005), "Study on the Effectiveness of Directive 1999/94/EC Relating to the Availability of Consumer Information on Fuel Economy and $\mathrm{CO}_{2}$ Emissions in Respect of the Marketing of New Passenger Cars," (accessed April 25, 2016), [available at http://ec.europa.eu/clima/policies/transport/vehicles/labelling/docs/final_report_en.pdf/].

Geiger, Constanze J., Bonita W. Wyse, C.R. Michael Parent, and R. Gaurth Hansen (1991), "Nutrition Labels in Bar Graph Format Deemed Most Useful for Consumer Purchase Decisions Using Adaptive Conjoint Analysis," Journal of the American Dietetic Association, 91 (7), 800-807. 
Goffin, Richard D. and James M. Olson (2011), “Is It All Relative? Comparative Judgments and the Possible Improvement of Self-Ratings and Ratings of Others," Perspectives on Psychological Science, 6 (1), 48-60.

Heath, Chip, Richard P. Larrick, and George Wu (1999), “Goals as Reference Points,” Cognitive Psychology, 38 (1), 79-109.

Heinzle, Stefanie Lena (2012), “Disclosure of Energy Operating Cost Information: A Silver Bullet for Overcoming the Energy-Efficiency Gap?” Journal of Consumer Policy, 35 (1), $43-64$.

and Rolf Wüstenhagen (2012), “Dynamic Adjustment of Eco-Labeling Schemes and Consumer Choice - the Revision of the EU Energy Label as a Missed Opportunity?" Business Strategy and the Environment, 21 (1), 60-70.

Hieke, Sophie and Charles R. Taylor (2012), “A Critical Review of the Literature on Nutritional Labeling," Journal of Consumer Affairs, 46 (1), 120-56.

Hutton, R. Bruce and William L. Wilkie (1980), "Life Cycle Cost: A New Form of Consumer Information," Journal of Consumer Research, 6 (4), 349-60.

International Energy Agency (2009), “Transport, Energy, and $\mathrm{CO}_{2}$," (accessed April 25, 2016), [available at https://www.iea.org/publications/freepublications/publication/transport2009.pdf/].

Jarvenpaa, Sirkka (1990), “Graphic Displays in Decision Making: The Visual Salience Effect," Journal of Behavioral Decision Making, 3 (4), 247-62.

Johnson, Eric J., John W. Payne, and James R. Bettman (1988), “Information Displays and Preference Reversals," Organizational Behavior and Human Decision Processes, 42 (1), $1-21$. 
—, Suzanne B. Shu, Benedict G. Dellaert, Craig Fox, Daniel G. Goldstein, Gerald Häubl, et al. (2012), "Beyond Nudges: Tools of a Choice Architecture," Marketing Letters, 23 (2), $487-504$.

Jones, Gary and Miles Richardson (2007), “An Objective Examination of Consumer Perception of Nutrition Information Based on Healthiness Ratings and Eye Movements," Public Health Nutrition, 10 (3), 238-44.

Jung, Janice Y. and Barbara A. Mellers (2016), “American Attitudes Toward Nudges,” Judgment and Decision Making, 11 (1), 62-74.

Kaenzig, Josef and Rolf Wüstenhagen (2010), “The Effect of Life Cycle Cost Information on Consumer Investment Decisions Regarding Eco-Innovation,” Journal of Industrial Ecology, 14 (1), 121-36.

Kahneman, Daniel and Amos Tversky (1973), “On the Psychology of Prediction,” Psychological Review, 80 (4), 237-51.

Kallbekken, Steffen and Håkon Sælen (2013), “'Nudging’ Hotel Guests to Reduce Food Waste as a Win-Win Environmental Measure," Economics Letters, 119 (3), 325-27.

Kalmbach, Ralf, Wolfgang Bernhart, Philipp Kleinmann, and Marcus Hoffmann (2012),

“Automotive Landscape 2025," (accessed April 25, 2016), [available at https://www.rolandberger.com/media/pdf/Roland_Berger_Automotive_Landscape_2025_ 20110228.pdf/].

Levy, Alan S., Sarah B. Fein, and Raymond E. Schucker (1996), "Performance Characteristics of Seven Nutrition Label Formats," Journal of Public Policy \& Marketing 15 (1), 1-15.

Liu, Peggy J., Jessica Wisdom, Christina A. Roberto, Linda J. Liu, and Peter A. Ubel (2014), "Using Behavioral Economics to Design More Effective Food Policies to Address Obesity," Applied Economic Perspectives and Policy, 36 (1), 6-24. 
Lurie, Nicholas H. and Charlotte H. Mason (2007), "Visual Representation: Implications for Decision Making," Journal of Marketing, 71 (1), 160-77.

Maan, Saskia, Bo Merkus, Jaap Ham, and Cees Midden (2011), “Making It Not Too Obvious: The Effect of Ambient Light Feedback on Space Heating Energy Consumption,” Energy Efficiency, 4 (2), 175-83.

McNeill, Dennis L. and William L. Wilkie (1979), "Public Policy and Consumer Information: Impact of the New Energy Labels," Journal of Consumer Research, 6 (1), 1-11.

Meissner, Martin, Stefanie Lena Heinzle, and Reinhold Decker (2013), "Not Worth the Extra Cost? Diluting the Differentiation Ability of Highly Rated Products by Altering the Meaning of Rating Scale Levels," Journal of Consumer Behaviour, 12 (3), 223-31.

Michalek, Gabriela, Georg Meran, Reimund Schwarze, and Özgür Yildiz (2015), "Nudging as a New 'Soft' Tool in Environmental Policy: An Analysis Based on Insights from Cognitive and Social Psychology," (accessed April 25, 2016), [available at https:/www.europauni.de/de/forschung/institut/recap15/downloads/recap15_DP021.pdf/].

Moller, Arlen C., Andrew J. Elliot, and Markus A. Maier (2009), “Basic Hue-Meaning Associations," Emotion, 9 (6), 898-902.

Nisbett, Richard E. and Lee Ross (1980), Human Inference: Strategies and Shortcomings of Social Judgment. Englewood Cliffs, NJ: Prentice Hall.

Ölander, Folke and John Thøgersen (2014), “Informing Versus Nudging in Environmental Policy," Journal of Consumer Policy, 37 (3), 341-56.

Payne, John W., James R. Bettman, and Eric J. Johnson (1993), The Adaptive Decision Maker. Cambridge: Cambridge University Press. 
Peters, Ellen, Nathan F. Dieckmann, Daniel Västfjäll, C.K. Mertz, Paul Slovic, and Judith H. Hibbard (2009), "Bringing Meaning to Numbers: The Impact of Evaluative Categories on Decisions," Journal of Experimental Psychology: Applied, 15 (3), 213-27.

— Judith H. Hibbard, Paul Slovic, and Nathan F. Dieckmann (2007), "Numeracy Skill and the Communication, Comprehension, and Use of Risk and Benefit Information," Health Affairs, 26 (3), 741-48.

Rao, Akshay R. and Kent B. Monroe (1989), "The Effect of Price, Brand Name, and Store Name on Buyers' Perceptions of Product Quality: An Integrative Review," Journal of Marketing Research, 26 (August), 351-57.

Ringold, Debra J. (2002), "Boomerang Effect: In Response to Public Health Interventions: Some Unintended Consequences in the Alcoholic Beverage Market," Journal of Consumer Policy, 25 (1), 27-63.

Roberto, Christina A. and Ichiro Kawachi (2014), "Use of Psychology and Behavioral Economics to Promote Healthy Eating," American Journal of Preventive Medicine, 47 (6), 832-37.

Selinger, Evan and Kyle Whyte (2011), "Is There a Right Way to Nudge? The Practice and Ethics of Choice Architecture," Sociology Compass, 5 (10), 923-35.

Sprott, David E., David M. Hardesty, and Anthony D. Miyazaki (1998), "Disclosure of Odds Information: An Experimental Investigation of Odds Format and Numeric Complexity,” Journal of Public Policy \& Marketing, 17 (1), 11-23.

Steinhart, Yael, Ziv Carmon, and Yaacov Trope (2013), "Warnings of Adverse Side Effects Can Backfire Over Time," Psychological Science, 24 (9), 1842-47.

Sunstein, Cass R. (2014), “Nudging: A Very Short Guide,” Journal of Consumer Policy, 37 (4), 583-88. 
(2015), "Nudging and Choice Architecture: Ethical Considerations," Yale Journal on Regulation, 32 (2), 413-50.

Swiss Federal Office of Energy (2015), “The Energy Label for Motor Vehicles,” (accessed April 25, 2016), [available at http://www.bfe.admin.ch/energieetikette/00886/index.html?lang=en/].

Taylor, Shelley E. (1982), "The Availability Bias in Social Perception and Interaction,” in Judgment Under Uncertainty: Heuristics \& Biases, Daniel Kahneman, Paul Slovic, and Amos Tversky, eds. Cambridge: Cambridge University Press, 190-200.

Teisl, Mario F., Jonathan Rubin, and Caroline L. Noblet (2008), "Non-Dirty Dancing? Interactions Between Eco-Labels and Consumers," Journal of Economic Psychology, 29 (2), 140-59.

Thaler, Richard and Cass Sunstein (2008), Nudge: Improving Decisions About Health, Wealth, and Happiness. New Haven, CT: Yale University Press.

— - - and John P. Balz (2013), "Choice Architecture" in The Behavioral Foundations of Public Policy, Eldar Shafir, ed. Princeton, NJ: Princeton University Press.

Thøgersen, John (2000), "Psychological Determinants of Paying Attention to Eco-Labels in Purchase Decisions: Model Development and Multinational Validation," Journal of Consumer Policy, 23 (3), 285-313. and Folke Ölander (2003), "Spillover of Environment-Friendly Consumer Behaviour," Journal of Environmental Psychology, 23 (3), 225-36.

Thorndike, Anne N., Jason Riis, Lillian M. Sonnenberg, and Douglas E. Levy (2014), “TrafficLight Labels and Choice Architecture: Promoting Healthy Food Choices," American Journal of Preventive Medicine, 46 (2), 143-49. 
Tiefenbeck, Verena, Thorsten Staake, Kurt Roth, and Olga Sachs (2013), "For Better or for Worse? Empirical Evidence of Moral Licensing in a Behavioral Energy Conservation Campaign," Energy Policy, 57 (June), 160-71.

Van Ittersum, Koert and Brian Wansink (2012), "Plate Size and Color Suggestibility: The Delboeuf Illusion's Bias on Serving and Eating Behavior,” Journal of Consumer Research, 39 (2), 215-28.

Viswanathan, Madhubalan, Manoj Hastak, and Roland Gau (2009), “Understanding and Facilitating the Usage of Nutritional Labels by Low-Literate Consumers," Journal of Public Policy \& Marketing, 28 (2), 135-45.

Waechter, Signe, Bernadette Sütterlin, Jonas Borghoff, and Michael Siegrist (2016), "Letters, Signs, and Colors: How the Display of Energy-Efficiency Information Influences Consumer Assessments of Products," Energy Research \& Social Science, 15, 86-95. $\longrightarrow, \ldots$, and Michael Siegrist (2015a), "Desired and Undesired Effects of Energy Labels: An Eye-Tracking Study," PlOs One, 10(7), 1-26.

$\longrightarrow, \ldots$, and — (2015b), "The Misleading Effect of Energy Efficiency Information on Perceived Energy Friendliness of Electric Goods," Journal of Cleaner Production, 93 (April), 193-202.

Wansink, Brian, Koert van Ittersum, and James E. Painter (2006), “Ice Cream Illusions Bowls, Spoons, and Self-Served Portion Sizes," American Journal of Preventive Medicine, 31, $240-43$.

Wiel, Stephen and James E. McMahon (2005), "Energy-Efficiency Labels and Standards: A Guidebook for Appliances, Equipment and Lighting (accessed April 25, 2016), [available at http://escholarship.org/uc/item/01d3r8jg.pdf/]. 
Wisdom, Jessica, Julie S. Downs, and George Loewenstein (2010), "Promoting Healthy Choices: Information Versus Convenience," American Economic Journal: Applied Economics, 2 (2), 164-78.

Yamamoto, Yoshihiro, Akihiko Suzuki, Yasuhiro Fuwa, and Tomohiro Sato (2008), "DecisionMaking in Electrical Appliance Use in the Home," Energy Policy, 36 (5), 1679-86. 


\section{Appendix A. Selection of Ecolabels for Vehicles Worldwide}

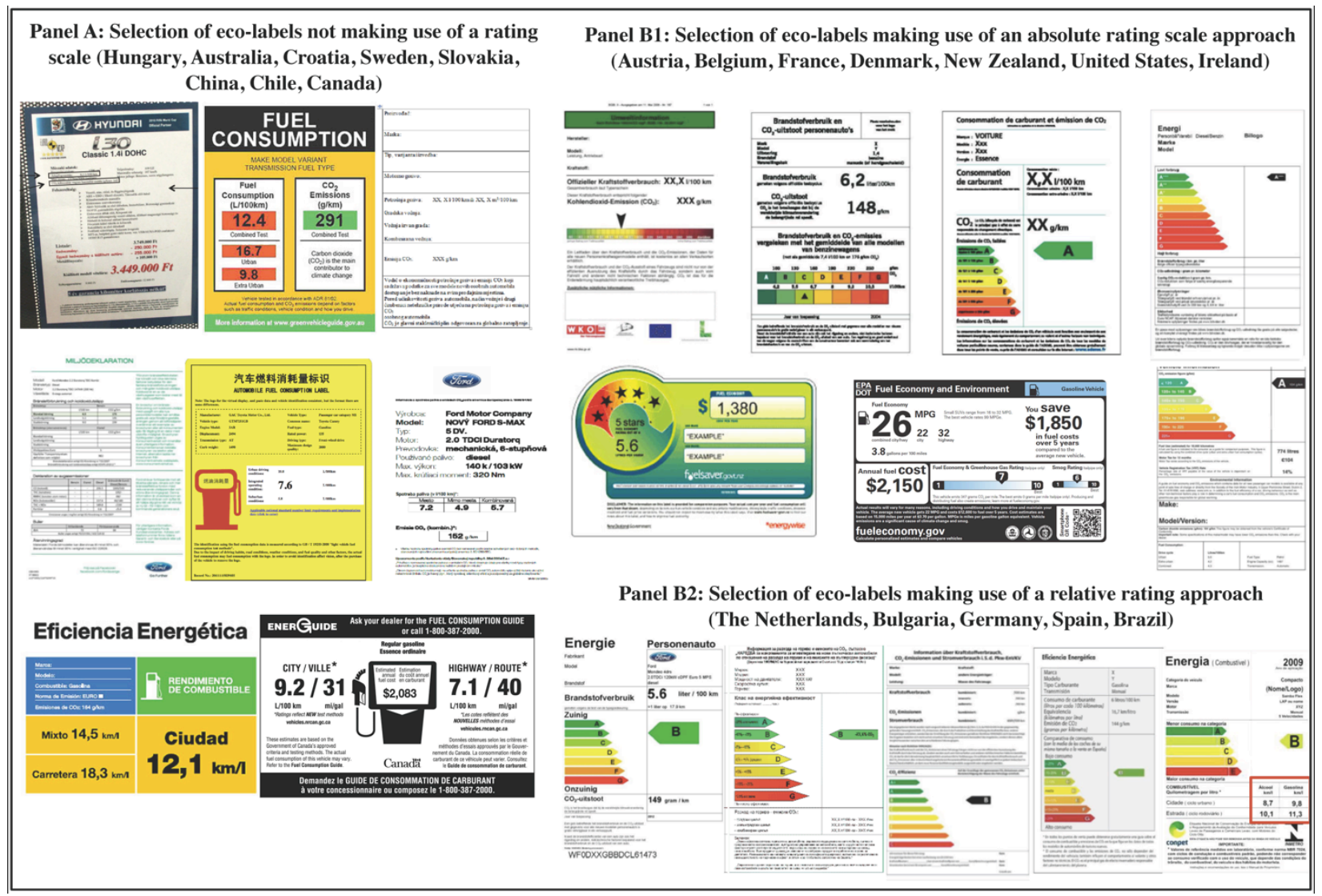


Figure 1. Study 1 Labels

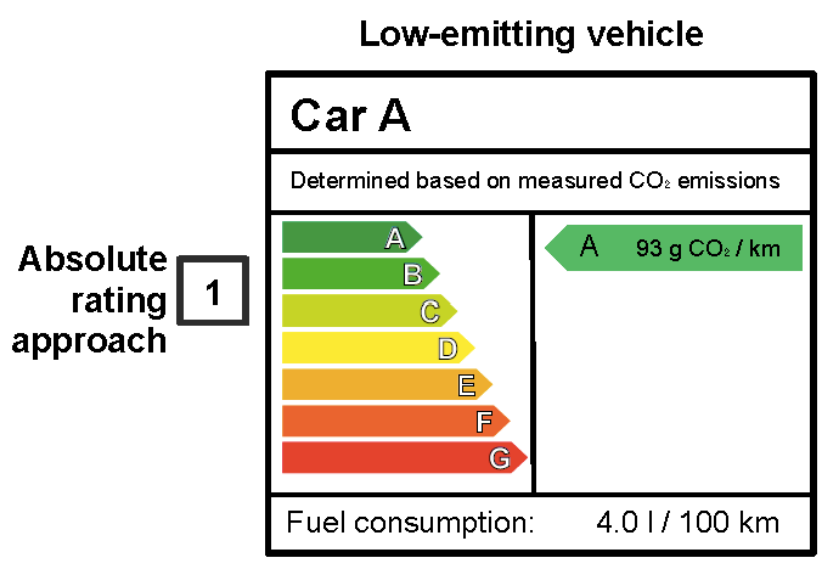

High-emitting vehicle
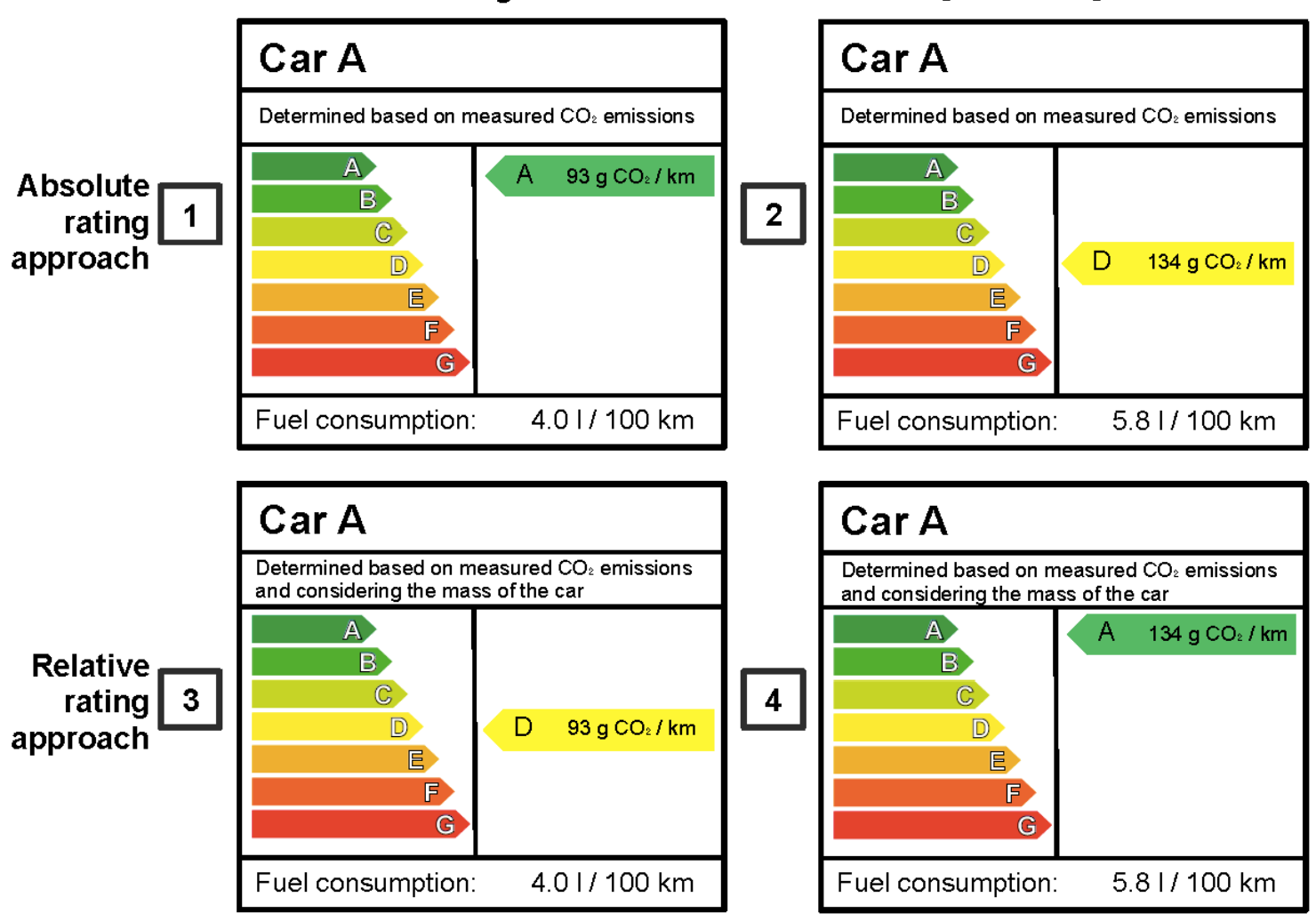
Figure 2. Study 1: A Relative Rating Approach Leads to a Reversal Effect

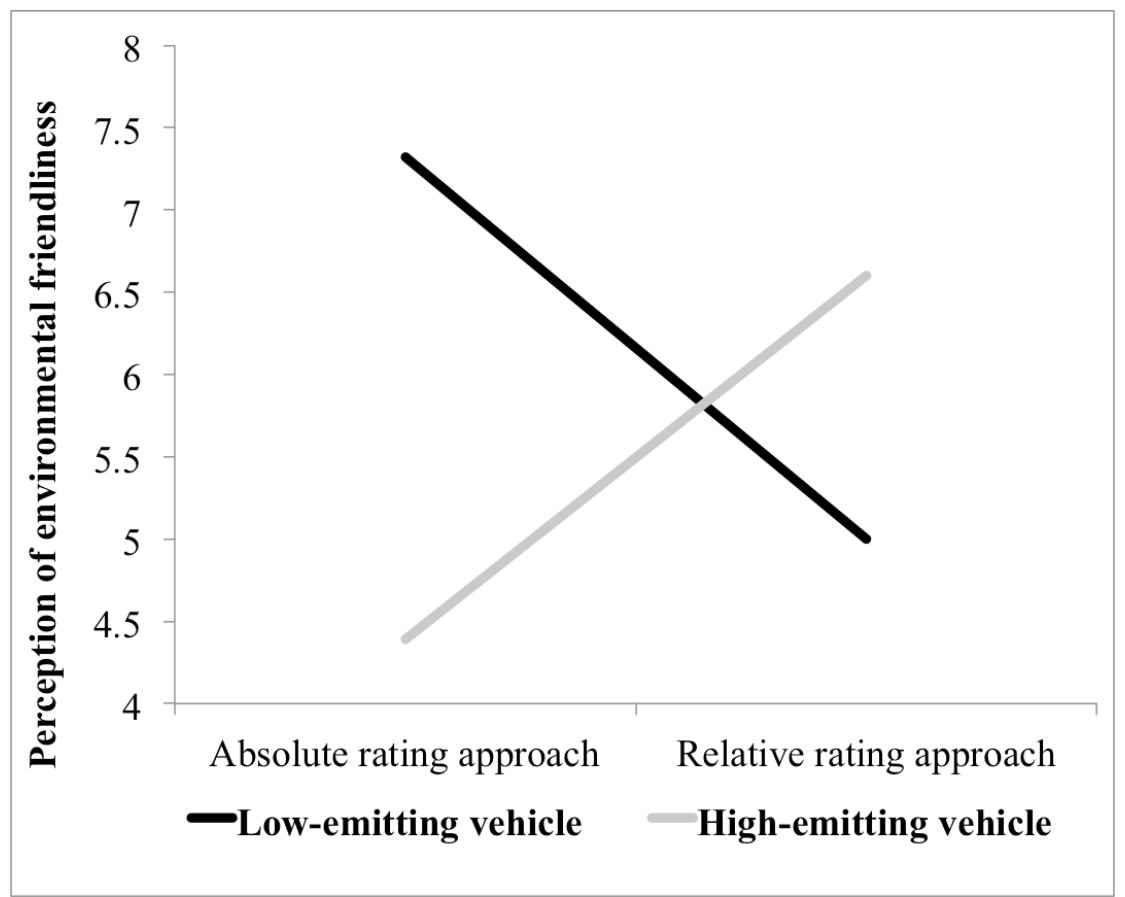


Figure 3. Study 2 Labels

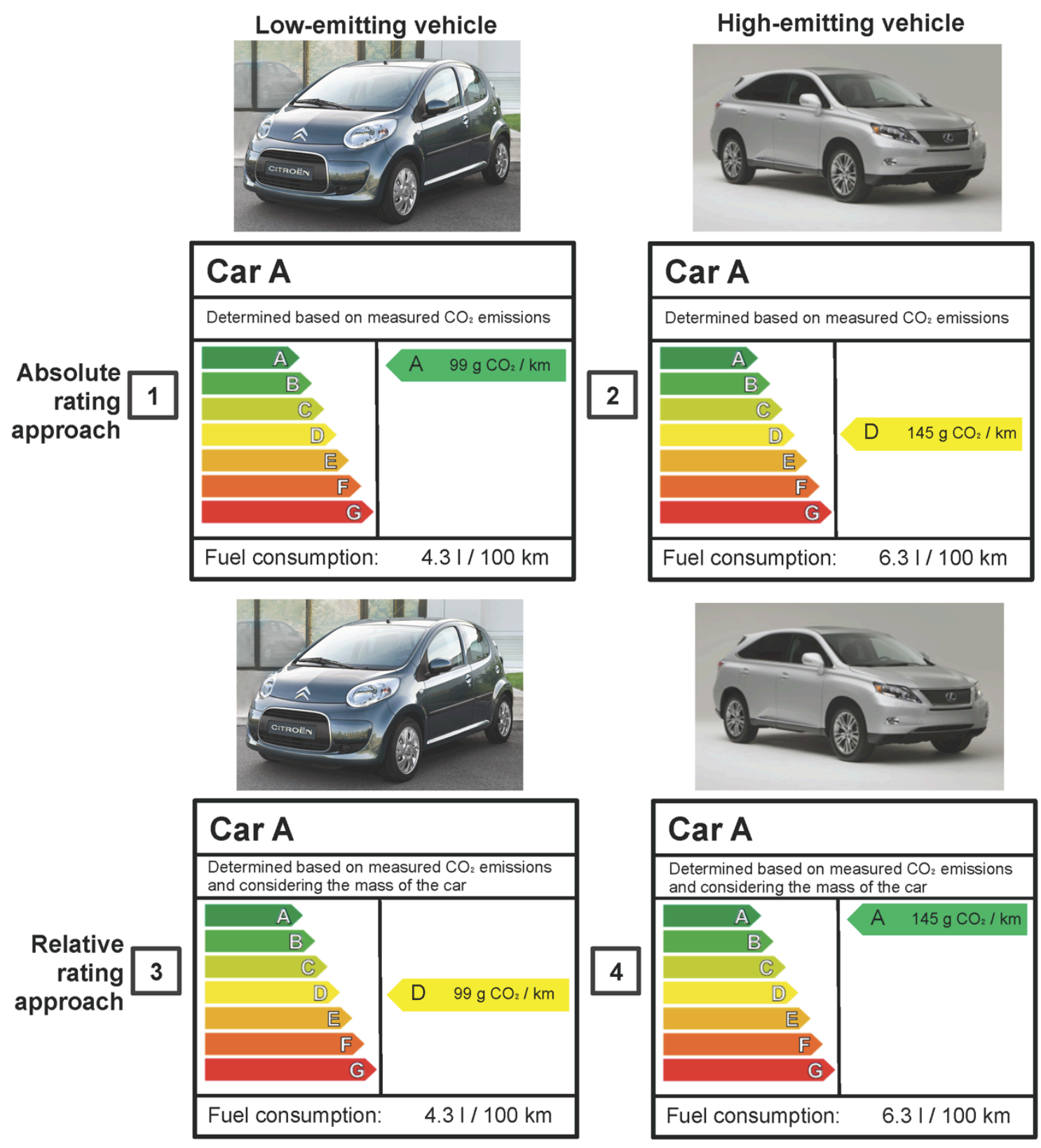


Figure 4. Study 2: Replication of Reversal Effect

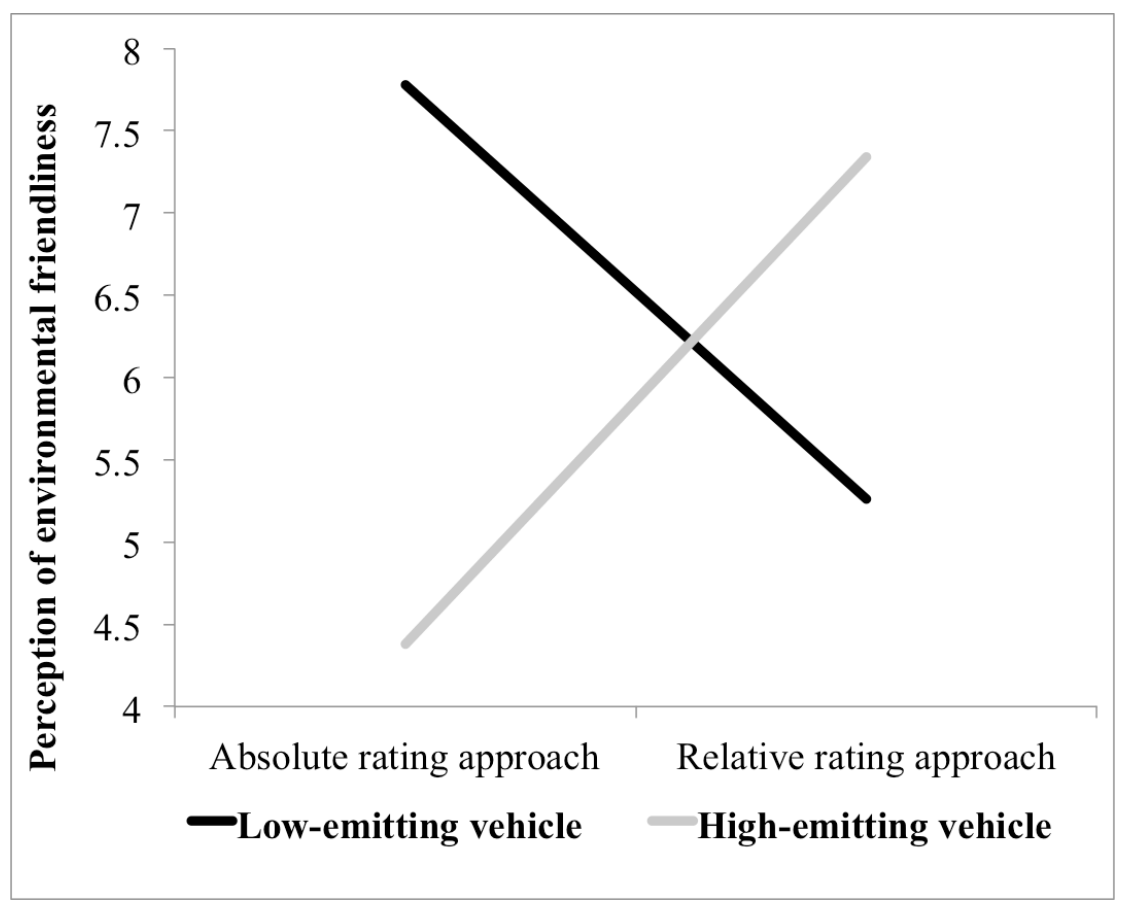


Figure 5. Study 3 Labels

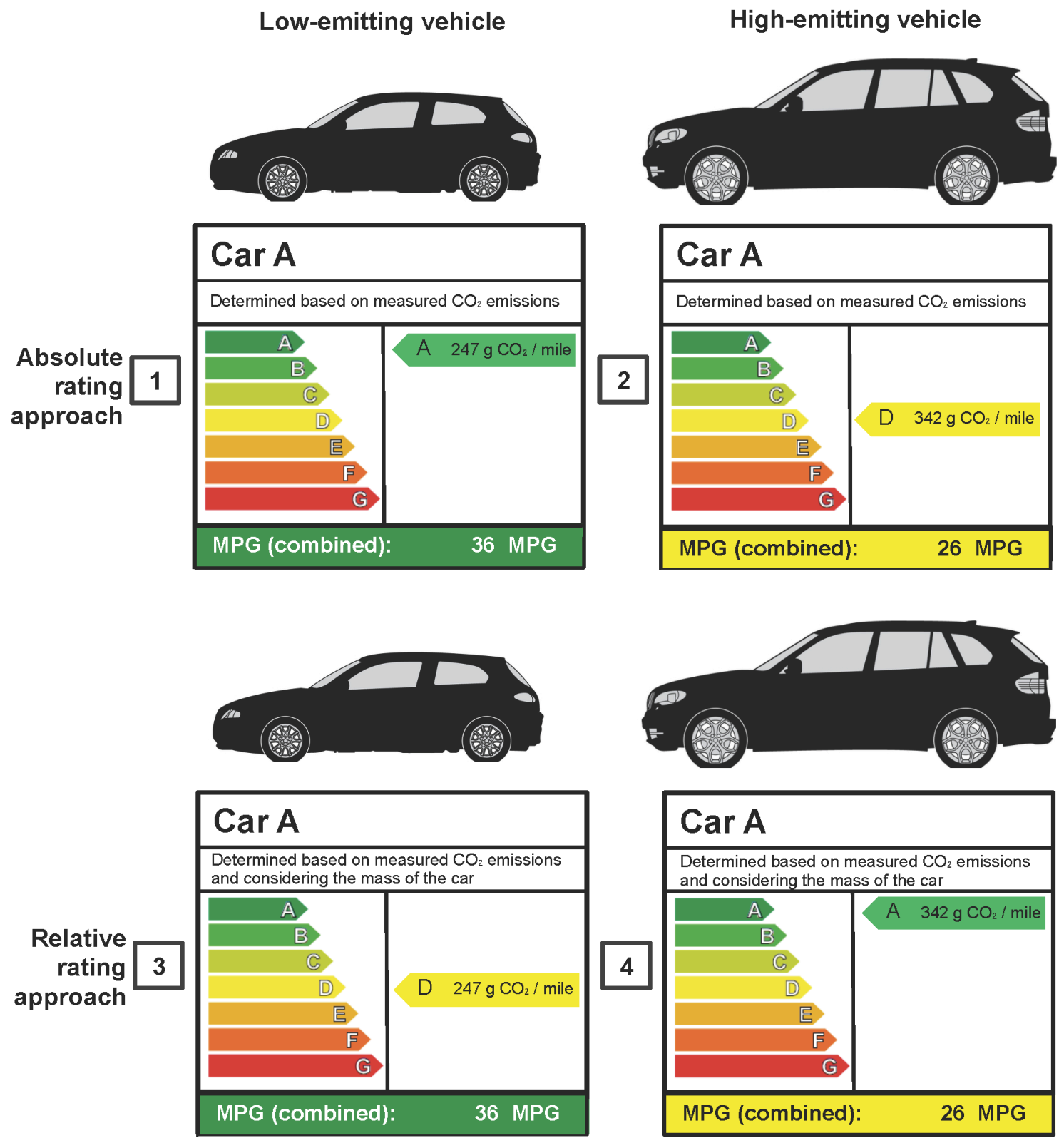


Figure 6. Study 3: Highlighting Mileage Does Not Correct Reversal Effects

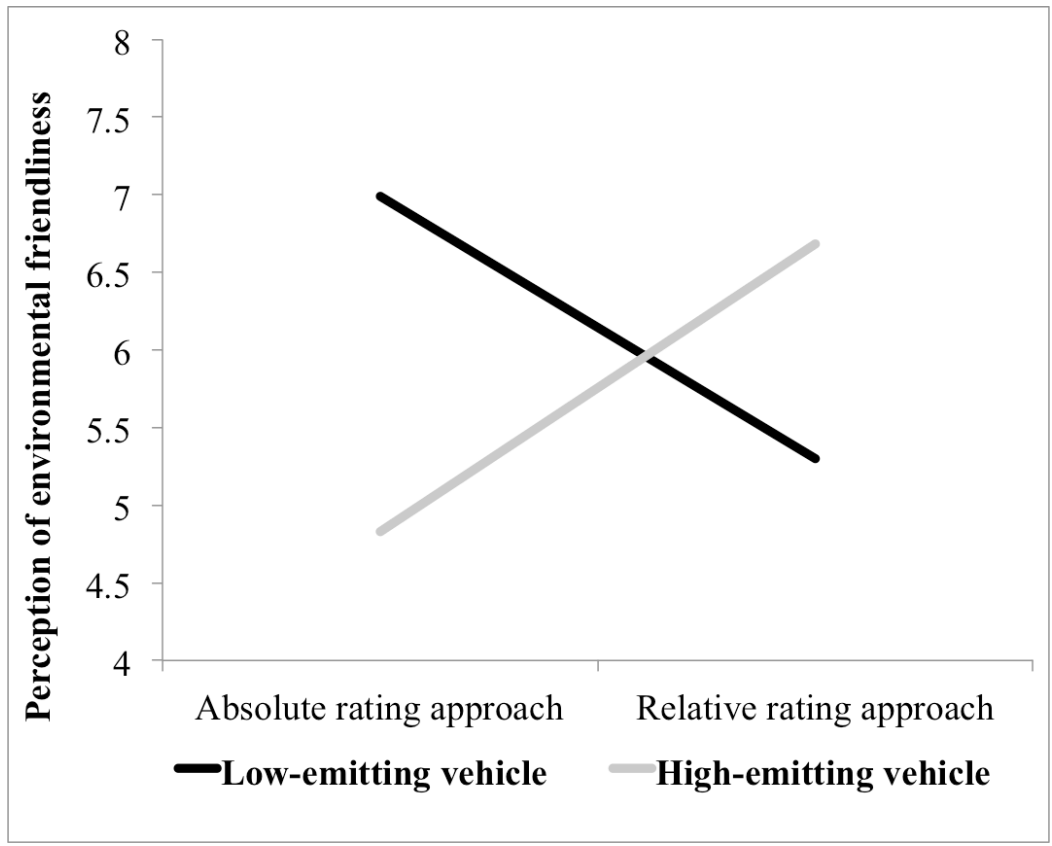


Figure 7. Study 4 Labels

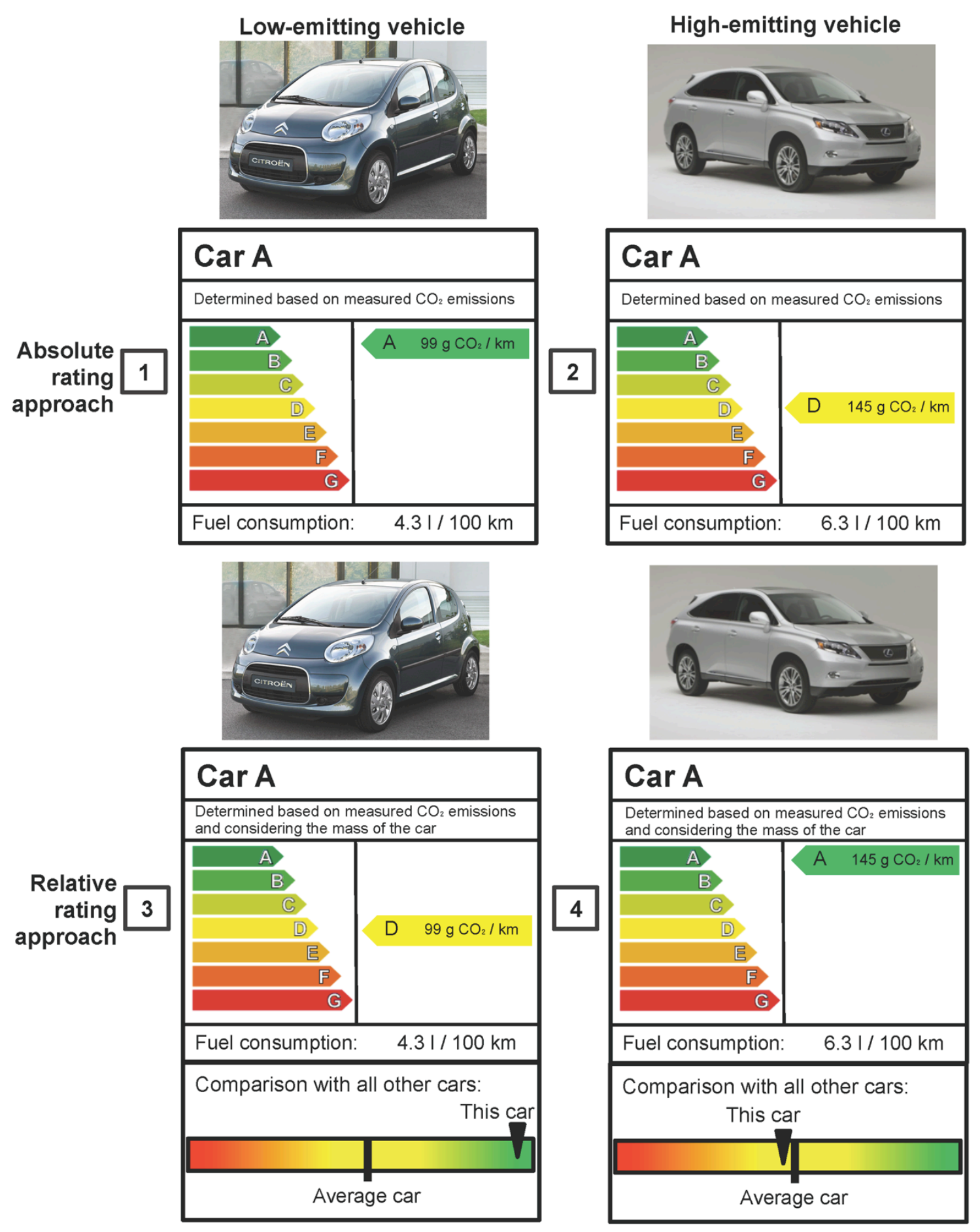


Figure 8. Study 4: Addition of Relative Performance Reduces but Does Not Correct

\section{Reversal Effects}

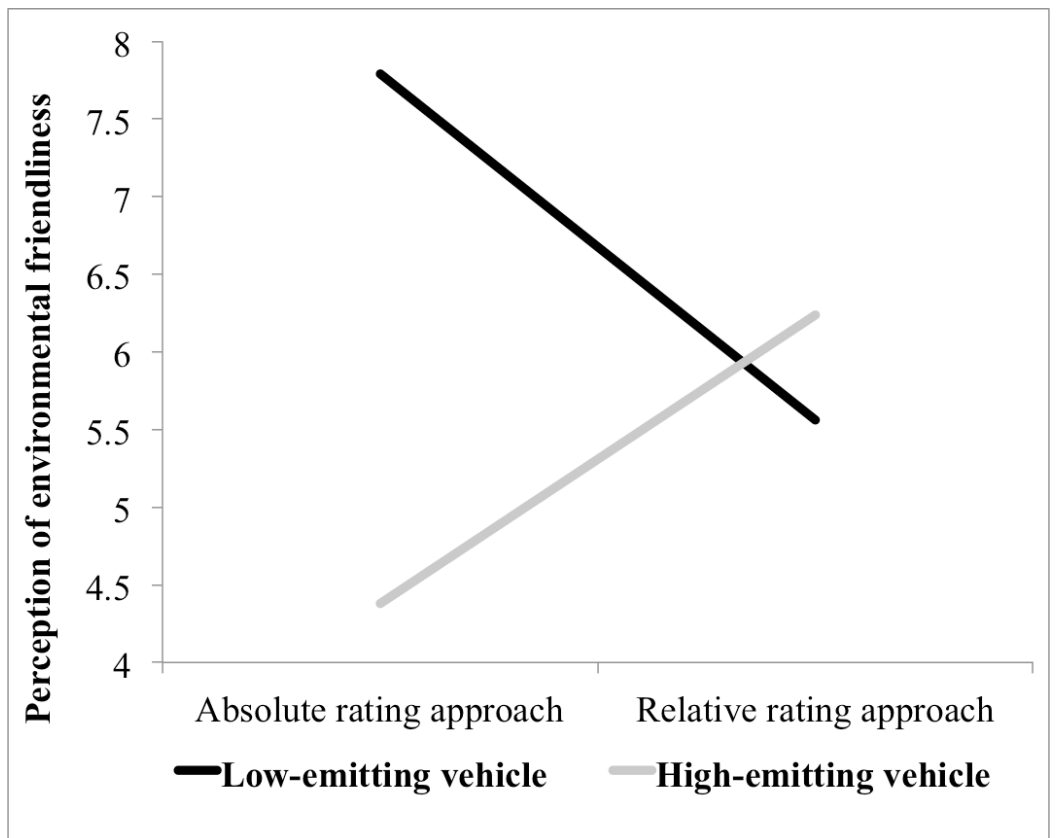

